\title{
El séptimo sello. \\ Una mirada fílmica sobre el silencio de Dios
}

Det sjunde inseglet | Ingmar Bergman | 1957

\section{Martín Agudelo Ramírez*}

Universidad Autónoma Latinoamericana, Colombia, y miembro Art-Kiné Internacional

Recibido: 10 de junio 2017; aceptado: 6 de septiembre 2017

Resumen

El séptimo sello (Det Sjunde Inseglet, 1957) es una película escrita y dirigida por Ingmar Bergman. El film es un retrato excepcional sobre el miedo padecido por el hombre contemporáneo frente al vacío agnóstico que amenaza constantemente su búsqueda de sentido. El director sueco acude a una metáfora medieval para expresar su desconcierto por no poder contemplar lo absoluto.

Palabras clave: Dios $\mid$ medioevo | nada | silencio | vacío agnóstico

A filming look about the silence of God

Abstract

The Seventh Seal (Det Sjunde Inseglet, 1957) is a film written and directed by Ingmar Bergman. The film is an exceptional portrait of the actual man's fear of the agnostic vacuum that constantly threatens his search for meaning. The Swedish director comes to a medieval metaphor to express his bewilderment at not being able to contemplate the absolute.

Key words: God | medioevo | nothing | silence | empty agnostic.

$1 .{ }^{1}$ La obra de Ingmar Bergman tiene un valor filosófico significativo. A partir de unas imágenes que sondean el espíritu, los monólogos, diálogos y silencios, las películas del director sueco abren paso a cuestiones de hondo calado, retratando dilemas humanos sobre el sentido de la vida. En esta dirección, uno de los problemas que más ocupó al realizador nórdico fue el del silencio de Dios, un ser del que no tenía certeza, y que parecía observar el mundo como un espectador sin intervenir.

Se destacan las películas de la conocida trilogía: Como en un espejo (1961), Los comulgantes (1963) y El silencio (1963), en las que Bergman hace pensar en la crisis de un ser agobiado por no hallar un fundamento que le dé sentido a su existencia. ${ }^{2}$ En esos films, el hombre se encuentra abocado por el absurdo, el sinsentido y la ausencia de comunicación. Según Javier Sicilia, en el caso de Bergman:

La presencia de Dios nace de los gestos oblativos, casi imperceptibles, de los protagonistas más desolados y débiles (...) Dios está ahí en su presencia nebulosa que sólo se capta a través de la opacidad del cristal de nuestras vidas, de la pequeña luz que pervive en el invierno sueco o en el fondo del silencio y de la incomunicación. ${ }^{3}$

Antes de esa trilogía sobre el silencio, Bergman había tratado el tema en una pieza maestra, El séptimo sello (Det Sjunde Inseglet, 1957), una obra monumental en la que el director nórdico puso en evidencia la dificultad de buscar certezas metafísicas. Para lograr ese propósito, Bergman recrea una historia basada en el ideario medieval, basándose en las obsesiones ya presentes desde su infancia.

Un niño acompañado de su padre, un pastor luterano, luego de contemplar lo que veía en las pequeñas iglesias cerca de Estocolmo, va reconociendo en su memoria las representaciones iconográficas de los frescos que se muestran en El séptimo sello. Son unas imágenes góticas las que inspiran a Bergman. Entre otras, se destacan las obras de Albertus Pictor, pintor del siglo XV, de la bóveda de la Iglesia de Täby, en Uppland, en las que se enseña a la muerte jugando ajedrez; también sobresalen pinturas sobre los flagelantes y la danza de la muerte.

* martinagramirez@gmail.com 
Estas manifestaciones artísticas cobrarían vida en un film de actualidad, en una película que hace visible el temor frente a la hecatombe nuclear, revelando un sentimiento de horror que no se diferenciaba del miedo que en la Europa Medieval se tuvo frente a la peste negra.

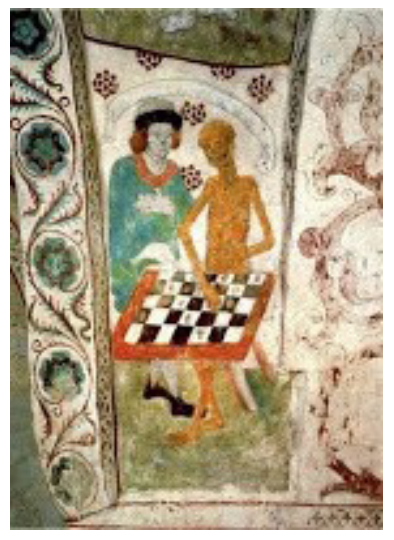

Al visionar la película, ganadora del premio especial del jurado del Festival de Cannes de 1957, es posible advertir una atmósfera agobiante. Se trata de un film muy personal, de profunda abstracción, que sume al espectador en un auténtico laberinto, haciendo pensar en lo que cabe esperar y en los límites que se ciernen cuando se busca contemplar lo absoluto.

El relato se va desarrollando a través de un guion de diálogos profundos, iniciados desde la puesta en escena de una singular partida de ajedrez hasta el final del film en el que se muestra una extraña danza de la muerte. De esta forma reconocemos una obra magnánima en la que se integran muy bien un texto escrito, dando cuenta de palabras y silencios para meditar, una fotografía en blanco y negro para contemplar, y una música inolvidable para no olvidar. ${ }^{4}$ Todo un simbolismo único se ofrece en la película, puesto en consideración del intérprete, desde el que resulta posible auscultar diversas perspectivas sobre su sentido y alcance.

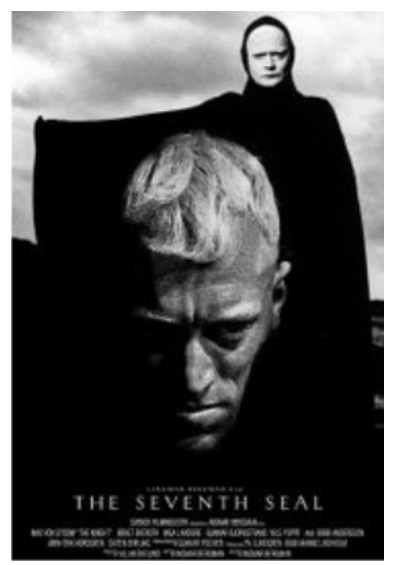

2. Estamos en Suecia. Es el siglo XIV. La peste negra ronda y la muerte se hace presente en una Europa decadente. Un aire gélido y letal acecha por todas partes. Desde el inicio de la película, con un plano en contrapicada, se evidencian unas imágenes sobrecogedoras acompañadas de una voz en off que pronuncia varios versículos del Apocalipsis $(8,1)$.

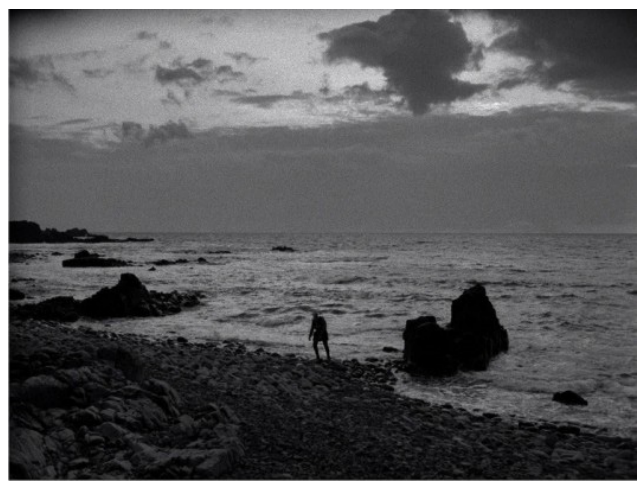

Un caballero que regresa de las Cruzadas, Antonius Block, se encuentra angustiado, confundido por tanta miseria; entre tanto su vida se desperdicia. El soldado, interpretado magistralmente por Max Von Sydow, le pide a la Muerte que le dé más tiempo de vida. Antonius quiere que su existencia se siga prolongando, mientras despeja varias dudas que lo han compungido durante muchos años, cuestiones decisivamente metafísicas y que se relacionan con el sentido de su vida. El alter ego del Bergman, a través de ese personaje central, comienza a explicitar sus conflictos internos, desatados en medio de pesadillas y de su apuesta firme por encontrar una salida que le permita entender la razón de su existir.

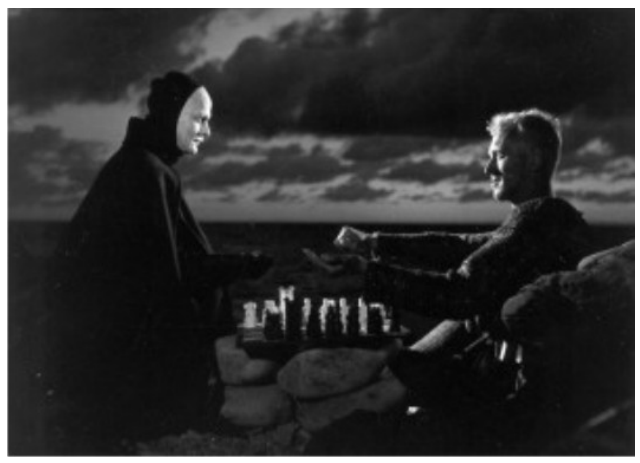

La Muerte, interpretada por Bengkt Ekerot, ante la resistencia de Antonius, decide suspender la partida de ajedrez que había iniciado; concede la prórroga solicitada por el caballero, y permite que este siga con su camino incesante de dudas. Antonius va abriendo su paso en medio de una atmósfera de profunda soledad y temor; le acompaña su escudero Jöns, personaje representado 
por Gunnar Björnstrand, un hombre de practicidad manifiesta, muy distante de las búsquedas metafísicas del caballero.

Los distintos personajes con los que se encuentran Antonius y Jöns dan una fuerza notoria al argumento de la película: una joven condenada por brujería; un antiguo profesor de teología y ahora ladrón de bienes de los muertos; la familia de juglares y titiriteros; una mujer joven salvada por el escudero de una violación; un herrero y su mujer infiel; y un grupo de flagelantes. La mayoría de los interlocutores de los soldados caminantes parecen inmersos en un mundo sombrío en el que se asienta la peste negra. Solo un grupo de ellos se salen de las reglas, la familia de comediantes, unos juglares que se orientan por la sabiduría popular y que buscan conducir sus vidas de forma sencilla. Antonius quiere salvarlos de la muerte, sabiendo que él no podrá escaparse de su destino.

Son momentos memorables de la película la procesión de los flagelantes y las escenas de Antonius con la bruja. Sobre lo primero, resulta inolvidable el encuentro de los guerreros andantes con unos penitentes que se dan latigazos y que están acompañados por monjes que cantan y llevan un crucifijo y un incensario. La gente rinde tributo a un paso ceremonial que busca aplacar la ira de Dios. Antonius, su escudero Jöns y los juglares no se arrodillan; al parecer, resisten frente a la torpeza de una fe ciega atrapada por la superstición. Uno de los monjes interviene y habla sobre la muerte en términos apocalípticos. El cortejo sigue su rumbo hasta que desaparece.

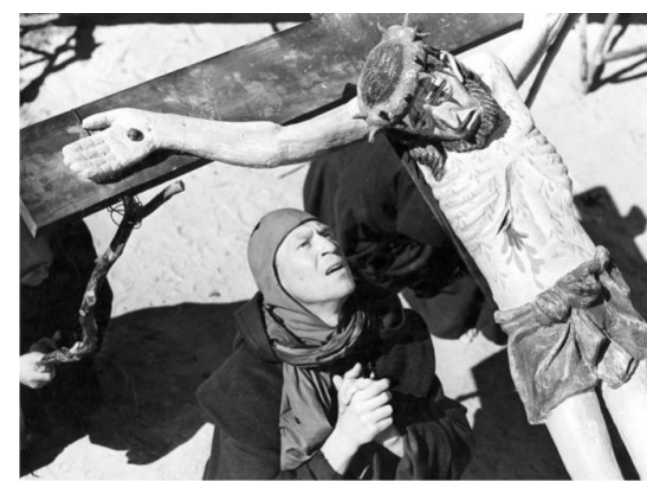

Las escenas de la bruja y de su ajusticiamiento son decisivas. Antonius revela su interés por la mujer condenada a la hoguera, acusada de tener relaciones con el diablo. Block pretende hablar con la joven, para que esta relate su experiencia con el demonio; piensa que la condenada puede disipar su angustia en atención a sus competencias con otras dimensiones y que, en sentir del caballero, podrían darle alguna razón sobre Dios. Block pretende que la muchacha despeje sus cuestionamientos sobre la posibilidad de vida después de la muerte. Sin embargo, el hombre mira hacia los ojos de la chica, atendiendo la sugerencia que le hace el escudero, sin que halle respuestas. El caballero solo ve un vacío profundo que le aterroriza; entretanto, en la mirada de la joven se va proyectando el horror.

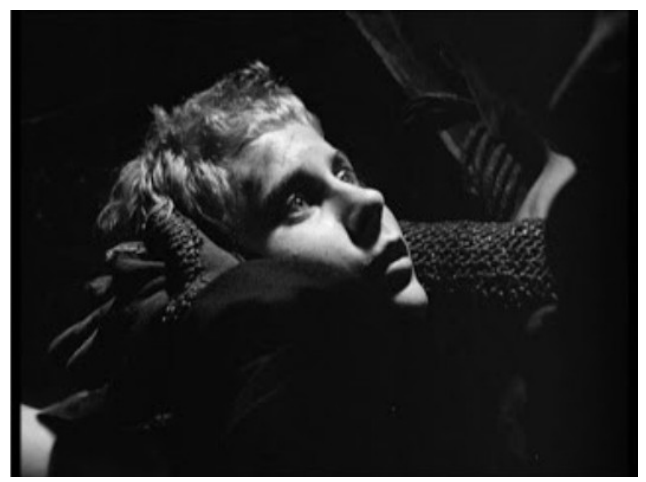

Al final de la película, concluye el viaje del caballero y sus acompañantes; llegan al castillo y la esposa de Antonius los recibe; leen el libro del Apocalipsis. Para entonces, el caballero había perdido la partida de ajedrez; se muestra cobarde en medio de los requerimientos de su escudero, que sigue increpándolo por la forma como se siente abarcado por el destino. La Muerte toma las vidas de Block y de varios de sus acompañantes; danza con ellos, de una manera macabra, abriendo paso a un nihilismo angustiante. No obstante, la pareja de trovadores, Jof y Mia, en compañía de su hijo, se salvan de esa ronda. Así acaba el film, y el espectador se encuentra sumido en un profundo estremecimiento.

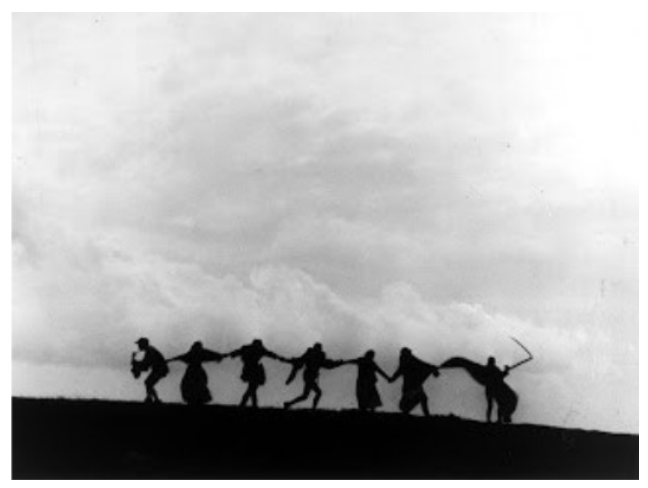

3. Bergman enseña que la medievalidad es un recurso legítimo para pensar sobre asuntos concernientes al trasegar del hombre contemporáneo. Temas como la duda y el vacío agnóstico son asuntos importantes, aún para quienes han sustituido el dilema sobre Dios por otro tipo de cuestiones. El realizador sueco sabe retratar esos temas, apelando a la iconografía del mundo medieval. En 
ese escenario el director enrostra la atmósfera de profundo estremecimiento que padece el hombre contemporáneo, como bien lo expresa Juan Miguel Company: "Ingmar Bergman ha querido escribir una alegoría sobre nuestro tiempo en forma de leyenda medieval. También se puede decir que ha tratado la situación del hombre: su eterna búsqueda de Dios con la muerte como única certidumbre". ${ }^{5}$

El séptimo sello no puede verse como un film con rigidez histórica. Los problemas que plantea "son esencialmente modernos: la película pertenece tanto a la "literatura del Día del Juicio" como al cine de la era atómica”, y "sus personajes centrales, el caballero y el escudero, son figuras claramente contemporáneas", así como los cómicos son "personajes intemporales" que parecen existir en una especie de valor absoluto". ${ }^{6}$ El film apela a la alegoría, dando cuenta de los miedos en los que el hombre se sumerge, no solo los de ayer; son también los temores que hoy se padecen. La obra se encuentra en sintonía con lo expuesto por Umberto Eco al considerar la Edad Media como la alborada del hombre actual.

Con una película, rica en metáforas, Bergman nos hace pensar en problemas de gran envergadura filosófica. El director logra su propósito recreando un ambiente agobiante que muestra la teatralidad en la que la muerte se desenvuelve, a través de la visión personal de una Europa bajomedieval con unas estructuras en franca decadencia. Es el ocaso que siempre ha acechado al hombre cuando ha buscado indagar por el sentido de su vida. No obstante, el realizador nórdico no se queda ahí; contrapone varios mundos.

En primer lugar, sobresale la oposición entre Block y Jöns, dos personajes singulares que replantean la mirada sobre el caballero y escudero medieval, como Quijote y Sancho. Block es un hombre idealista como el noble hidalgo de la Mancha, un ser insatisfecho que busca constantemente; sin embargo, el caballero de Bergman se encuentra más atormentado por el vacío agnóstico. El escudero es su antítesis; un hombre incrédulo y sin preocupaciones metafísicas. Bergman retrata a Jöns como un hombre práctico, que reconoce la naturaleza perversa de la condición humana; el escudero es impúdico e insolente, como bien se presenta en el film: "Aquí tienes al escudero Jöns. Se ríe de la muerte, blasfema de Dios, se burla de sí mismo y sonríe a las mujeres. Su mundo es solo el mundo de Jöns, un pobre bufón ridículo para todos e incluso para sí mismo. Tan indiferente es para el cielo como para el infierno". El canto del escudero es revelador; para él: "No existe el destino, estáis ante la nada..."
Jöns solo se preocupa por la vida presente cerrando paso a la esperanza y a cualquier idea de un mundo mejor.

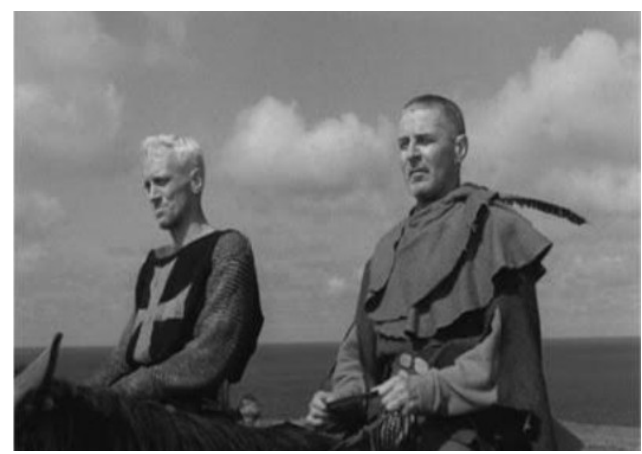

De esta manera, el contraste entre los dos personajes está claramente planteado, como Robin Wood lo precisa:

Caballero y escudero, unidos en el combate, represen$\tan (\ldots)$ valores antitéticos. El escudero despecha al caballero cantando una canción obscena ("entre las piernas de una prostituta”), que expresa una aceptación estoica de la muerte y los valores puramente materialistas. El caballero es, por el contrario, un hombre insatisfecho, siempre a la búsqueda de algo que jamás encuentra. El escudero anuncia terribles presagios (“cuatro soles en el cielo", etc.), relacionados con la visión de Apocalipsis del Juicio Final. ${ }^{7}$

Otro asunto para destacar es que Bergman tiene claro que medievo no solo fueron cruzadas, caballeros, escuderos, inquisición, brujas y hogueras. El director insiste en la riqueza del mundo de los comediantes y juglares, un mundo en el que la risa se hace visible. La seriedad se contrapone a la carcajada, en los términos explicados por Bajtin. El oscurantismo de los caballeros, de las cruzadas, de la muerte y del ambiente reinante en la Suecia medieval contrasta con la alegría de unos personajes ingenuos y llenos de vida, seres que con sus vestidos de blanco resisten frente a una cosmovisión de sombras que pretende absorberlos. Los juglares permiten que la luz abra paso a una opción de esperanza, representada en el amor.

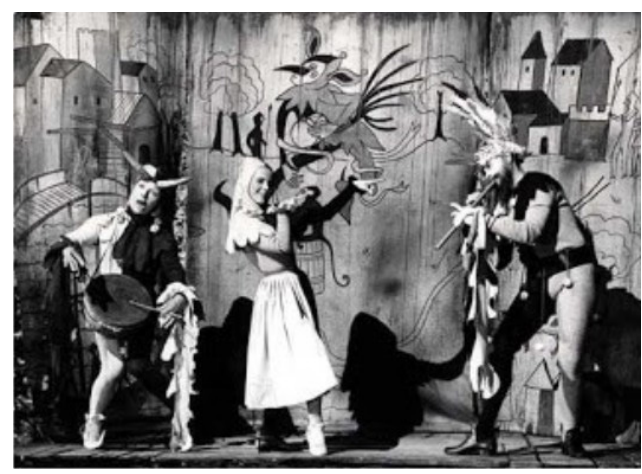

4. Ahora bien, cuando se reflexiona sobre los dilemas que Bergman se plantea sobre el miedo a la muerte, es 
posible entender que la película es un testimonio fehaciente de un director y guionista sobre sus obsesiones; es un acto público de confesión ante terceros sobre una experiencia de caída y profunda soledad. La muerte implica la desaparición del mundo de los sentidos, constituyéndose en un límite de la existencia. Bergman sabe interpelar a sus espectadores a través de las voces desesperadas de sus personajes.

Al director nórdico le resultaba bien difícil asimilar la idea del fin de la existencia; sin embargo, encontró en el cine un espacio único para expresar sus temores y aprietos en la comprensión de un momento que es tan cierto que llegará. Pero ahí no queda todo. El reconocimiento de un límite de la existencia, hacía que el realizador dudara de las posibilidades de la eternidad, lo que no impedía seguir indagando, en medio de tanta confusión, sobre si valía la pena considerar el sentido de la vida humana.

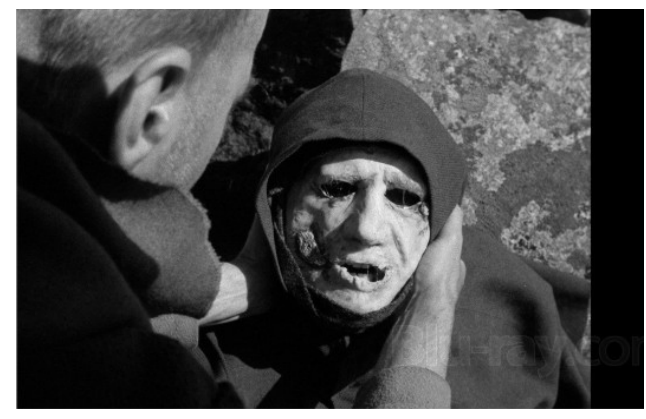

Para Bergman, el miedo a la muerte conduce indefectiblemente a la pregunta religiosa sobre la existencia de Dios; pero la película no responde a la cuestión, solo permite indagar sin cesar sobre el asunto. La confusión sobresale, siendo necesario generar un embate frente a la apabullante superficialidad que azota al hombre actual. No hay certezas sobre lo que sucederá una vez llegue la muerte. El ser humano no halla a Dios para que le responda. Está solo. Por esto, desde la perspectiva del director, se piensa que todo aquel que aborde dilemas de esa entidad estará amenazado por la posibilidad de hundirse en un "espantoso" abismo.

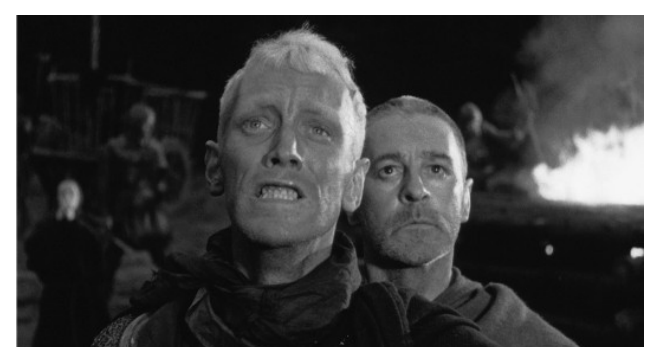

La cordura está comprometida. En la película la muerte acecha, está por toda parte; los ritmos y términos de la partida de ajedrez es lo único que puede aplazarla. Sin embargo, el asalto final llega. La suerte está echada. Por esto, Bergman es consciente del vacío agnóstico que le amenaza; siente que sus convicciones morales y religiosas están tambaleando por el silencio de Dios. El realizador nórdico trata de entender en qué términos una capa densa de enorme vacío viene desmoronando los pisos ideológicos con los que había buscado interpretar el sentido de la vida.

Cuando se consideran cuestiones sobre el alcance del sentido y la conciencia de un individuo, como las que se presentan en la película de Bergman, es posible plantear puentes con el pensamiento existencialista de Kierkegaard y Sartre. Hay un espacio para el reconocimiento de la libertad, y que permite indagar sobre la muerte en relación con la finitud del ser humano. Se profundiza un vacío desgarrador, desde el que se cuestiona la importancia de la religiosidad y la posibilidad de plantear la fe sin actos de religión. No obstante, Bergman no encuentra esas respuestas, como tampoco la muerte pudo responderle a Block.

5. Ahora bien, volviendo al punto basilar de la película, sobre el silencio de Dios, si bien el hombre contemporáneo ha buscado superar el problema de Dios, esto no significa que no se sigan manifestando ciertas preocupaciones religiosas. Bergman lo pone en evidencia. Claro está que, para el momento de la película, el director tenía unos intereses muy marcados por develar algo que poco a poco se le iba escapando; pero su certeza frente a la muerte impedía su indiferencia total. Se trata del propio horror de un director para una época en que, como él mismo lo expresa, aún le "quedaban algunos raquíticos restos" de su "devoción infantil, una idea absolutamente ingenua de lo que se podía llamar una salvación que no es de este mundo." Según Bergman: "El ser humano lleva en sí su propia Santidad, una Santidad que es de este mundo y no tiene explicación fuera de él. En mi película vive, pues, un resto bastante poco neurótico de una devoción sincera e infantil. Coexiste en paz con una concepción de la realidad dura y racional". ${ }^{8}$ No obstante, la ausencia de Dios se iba haciendo cada vez más notoria, y los films posteriores así lo mostraron, como lo revela su trilogía sobre el silencio. ${ }^{9}$

En Bergman, el conocimiento de Dios no logra obtenerse racionalmente; pero la fe revela profunda congoja por su manifiesta fragilidad. Lo expresa el Caballero al expresar su angustia por no lograr matar a Dios, un ser que sigue habitando en su interior, pese a sus maldiciones que pretenden eliminarlo. 
Quiero confesarme y no sé qué decir. Mi corazón está vacío. El vacío es como un espejo puesto delante de mi rostro. Me veo a mí mismo, y al contemplarlo siento un profundo desprecio de mi ser (...) por mi indiferencia hacia los hombres y las cosas me he alejado de la sociedad en que viví. Ahora habito un mundo de fantasmas, prisionero de fantasías sin sueños.

El caballero, amenazado constantemente por la nada, quiere entender; expresa su tormento por haber "gastado" su vida; por encontrar que su vida ha sido un "continuo absurdo". Block expresa que no se debe afirmar lo que no se logra demostrar y que nadie puede vivir sabiendo que camina a la nada. El caballero atormentado lo afirma de manera contundente al expresar: "Nadie puede vivir mirando la muerte y sabiendo que camina hacia la nada". Las tinieblas lo acechan. Antonius se siente atrapado por la angustia de querer tener certeza de Dios y no hallarla; siente que no tiene "garantías". Su conciencia de vida vacía le resulta insoportable; el influjo de Kierkegaard es manifiesto.

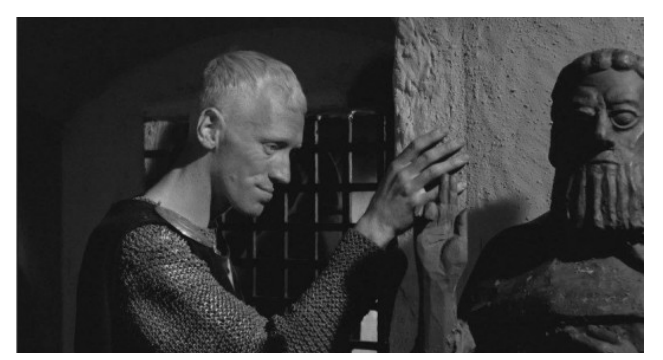

El texto del guión es lo suficientemente explícito.

¿Por qué, al menos, no me es posible matar a Dios en mi interior? ¿Por qué prefiere vivir en mí de una forma tan dolorosa y humillante, puesto que yo le maldigo y desearía expulsarlo de mi corazón? ¿Sabes? Estoy a punto de llegar a una conclusión. Creo que Dios es una especie de realidad engañosa, de la cual los hombres como yo no podemos desprendernos (...)

Por ello, yo quiero saber. No deseo creer. Ni suponer, sino saber... Deseo que Dios me tienda su mano, ver su rostro y que me hable (...)

Nadie es capaz de vivir con la Muerte ante sus ojos y creyendo que todo ha de desembocar en la nada más absoluta (...)

Mi vida ha sido algo completamente vacío, sin sentido. He cazado, he viajado, he convivido con todo el mundo. Pero todo ha sido inútil... Lo digo sin vergüenza y sin remordimiento, porque sé que la vida de los hombres está hecha así. Es precisamente por eso por lo que deseo utilizar mi aplazamiento: para realizar, aunque sólo sea un único acto que tenga alguna significación.

Los sentidos no pueden responder a preguntas metafísicas de tanto calado, ni la razón puede acercarse a ámbitos en donde solo cabe la fe. El fragmento de la escena de la bruja resulta definitivo. En la mirada de la joven, el caballero solo ve vacío, profunda soledad ante la imposibilidad de tener certezas sobre lo que hay más allá de la muerte. El silencio de Dios, un ser sobre el que no se tiene certeza y que, de pronto, observa el mundo como espectador sin intervenir termina por comprometer la cordura de Antonius.

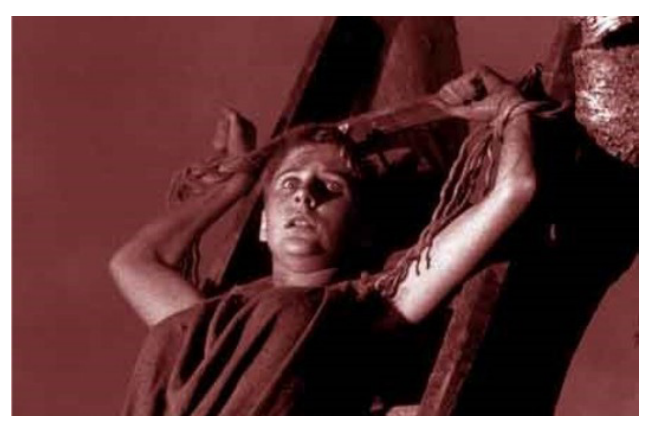

6. A modo de conclusión, vale destacar que El séptimo sello, una película de actualidad indiscutible, es un testimonio de resistencia frente a cualquier pretensión de renuncia a la cuestión sobre el sentido de la vida. El film es una auténtica obra de arte, una pieza icónica y metafórica, que no tiene como propósito ofrecer juicios morales, ni responder certeramente a preguntas de hondura metafísica.

No obstante, la obra presenta una alternativa para continuar existiendo en medio de la amenaza de locura. $\mathrm{El}$ amor ofrece una opción para escapar del sinsentido; es la causa para que el arte y la comedia mantengan el optimismo en sus participantes. Vacío y desolación podrían llenarse con amor, y esto lo enseña Bergman con los juglares, como también en películas posteriores.

El amor es lo único que puede salvar al hombre de la incomunicación. La soledad no tiene por qué ser punto de llegada; por esto, el apartamiento de los seres humanos no puede ser fin de la existencia. Aunque la angustia sea su compañera inseparable, la existencia puede ser más llevadera cuando hay comunicación; no importa que se den numerosos desencuentros. Hay un quiebre frente a las miradas de Schopenhauer y Sartre. La incomunicación es soledad total, fin, aunque se reconozca lo difícil que resultan las relaciones humanas. Se advierte un existencialismo de profundo contenido religioso, en medio de la duda y la fe.

Sin embargo, aunque el amor sea lo único que puede salvarnos de la incomunicación, no es fácil emprender una apuesta por este sentimiento. En este sentido resultan memorables las palabras del escudero. El hombre incrédulo de la historia, Jöns, hace manifiesto sin ambages las contradicciones que se advierten cuando se apela al amor. $\mathrm{El}$ amor es lo más perfecto por su perfecta imperfección. 


\section{Referencias}

Agudelo Ramírez, Cine y derechos humanos; una aventura fílmica, Unaula, Medellín, 20105.

Bergman, Ingmar, Imágenes, tr. de J. Uriz Torres y F. Uriz, 2ed., Tusquets, Barcelona, 2007

Company, Juan Miguel, Ingmar Bergman, Madrid, Cátedra, 2007.

Sicilia, Javier, Ingmar Bergman, la trilogía sobre Dios, Sempre, 27 de mayo de 1999.

Sojo Gil, Kepa, “Pecado, muerte y existencialismo en El séptimo sello de Ingmar Bergman. El problema divino en el cine nórdico”, 2010. Consultado el 1-05-2016 en: https://www.durango-udala.net/porta...

Wood, Robin, Ingmar Bergman, Fundamentos, Madrid, 1972.

\section{Filmolgrafía}

Det sjunde inseglet (The Seventh Seal), Suecia, 1957. D. Ingmar Bergman. G. Ingmar Bergman. M. Erik Nordgren. I. Max von Sydow, Gunnar Björnstrand, Bibi Andersson, Nils Poppe, Bengt Ekerot, 96 m. B/N.

1 En este artículo desarrollo lo expuesto en la ponencia presentada en el XVI Congreso Latinoamericano de Filosofía Medieval, Santiago, 24-26 de agosto de 2017.

2 I. Bergman, Imágenes, tr. de J. Uriz Torres y F. Uriz, 2ed., Tusquets, Barcelona, 2007, p. 215.

3 J. Sicilia, Ingmar Bergman, la trilogía sobre Dios, Sempre, 27 de mayo de 1999.

4 Sobresale la partitura de Erik Nordgren y la inolvidable composición El "Dies Irae” de Tomás de Celano, contraponiendo gozo con temor, esperanza con juicio frente a la postrimería inminente.

5 J. M. Company, Ingmar Bergman, Cátedra, Madrid, 2007, p. 25.

$6 \quad$ R. Wood, Ingmar Bergman, Fundamentos, Madrid, 1972, p. 91.

$7 \quad$ Ibíd, p. 88.

$8 \quad$ I. Bergman, op. cit., pp. 204-207

9 La vida, sin embargo, le mostrará a Bergman que su existencia seguirá fundida a cierta apuesta por la esperanza. Bergman realiza su propia terapia. Si bien considera que "somos una luz que está encendida y luego la vida se extingue", agregando que "Nada queda, ninguna llama", acepta que la posibilidad de volver a ver la mujer amada. "Volveré a ver a Ingrid”. Ingmar Bergman \& E. Josephson - Reflexiones sobre la vida, la muerte y el amor”, consultado el 07/05/17 en: https://www.youtube.com/watch?v=HqT... 